\title{
An Individualized Approach to Abdominoplasty in the Presence of Bilateral Subcostal Scars after Open Gastric Bypass
}

\author{
Ulrich M. Rieger • Paolo Erba • \\ Daniel F. Kalbermatten • Dirk J. Schaefer • \\ Gerhard Pierer • Martin Haug
}

Received: 12 December 2007 / Accepted: 27 December 2007 / Published online: 3 April 2008

(C) Springer Science + Business Media, LLC 2008

\begin{abstract}
Background Patients requiring surgical skin excision after massive weight loss are challenging and require an individualized approach. The characteristic abdominal deformity includes a draping apron of panniculus, occasionally associated with previous transverse surgical scars from open gastric bypass surgery in the upper abdomen, which compromise blood supply of the abdominal skin.

Methods We propose four different surgical techniques for safe abdominal body contouring in the presence of such scars: (1) a limited abdominoplasty of the lower abdomen is performed, and then contouring is completed by a reversed abdominoplasty with scar positioning in the submammary folds; (2) a one-stage procedure characterized by skin resection in the upper and lower abdomen, in which blood supply of the skin island between the submammary and suprapubic incisions is ensured by periumbilical perforators; (3) a perforator-sparing abdominoplasty with selective dissection of periumbilical abdominal wall perforators to secure flap blood supply and allow complete flap undermining up to the xyphoid process; (4) for patients with extensive excess skin, a modified Fleur-de-Lys abdominoplasty performed in such a way that the old transverse scar is transformed into a vertical scar.

Results The treatment of four exemplary patients is described. All techniques yielded good esthetic and
\end{abstract}

U. M. Rieger $(\bowtie) \cdot$ P. Erba • D. F. Kalbermatten • D. J. Schaefer G. Pierer $\cdot$ M. Haug

Department of Plastic, Reconstructive and Aesthetic Surgery, University Hospital of Basel,

Spitalstrasse 21, 4031 Basel, Switzerland

e-mail: riegeru@uhbs.ch functional results through preservation of abdominal blood supply.

Conclusion Through an individualized approach, adequate abdominal body contouring can be performed safely, even in the presence of transverse surgical scars in the upper abdomen.

Keywords Abdominoplasty · Subcostal scar - Obesity . Open gastric bypass

\section{Introduction}

In patients being referred for abdominoplasty after gastrointestinal bypass surgery, we occasionally encounter a long transverse supraumbilical or subcostal scar that compromises blood supply from the superior epigastric arteries. The left oblique or left and right oblique incisions have become standard incisions in bariatric surgery because they have a very low rate of incisional hernia compared to vertical midline incisions [1-3]. In a study by De Castro et al. [4] on full abdominoplasties in previously scarred abdomens, the authors note that the supraumbilical scar limiting abdominal flap blood supply is associated with a higher rate of postoperative complications. The scars and the subdermal fibrosis occurring after open gastric bypass surgery is responsible for jeopardizing the blood supply of the abdominal flap and increases the risk of abdominal flap necrosis. For these reasons, often a limited abdominoplasty of the low transverse type with undermining only up to the level of the umbilicus is performed in order not to compromise blood supply in the zone between the old transverse and the new transverse scar. Limitation of mobilization of the abdominal flap leads to preservation 
of vascular zones [5], but not to an esthetically and functionally acceptable result. Often a panniculus draping over the subcostal incision persists, causing uncomfortable skin-to-skin contact with the risk of intertrigo. To achieve effective body contouring after gastrointestinal bypass surgery, soft tissue mobilization above the umbilicus is required. As the removal of massive soft tissue excess in the presence of scars in the upper abdomen requires an individualized approach, we propose four different operative techniques, which yield an adequate abdominal body contour by the preservation of abdominal flap vascularization.

\section{Materials and Methods}

Operative Techniques

1. Abdominoplasty - cranial and caudal incision-twostaged procedure

In a first procedure, a limited low transverse abdominoplasty with undermining up to the umbilicus and excess skin resection is performed. Six months later at the earliest, a second procedure consisting of an inverted abdominoplasty with scar positioning in the
Fig. 1 Abdominoplasty, twostaged procedure. (a) Preoperative views (frontal/lateral). (b) Six months postoperatively (frontal/lateral): preoperative views for second intervention (note: scar resulting from first operative step: abdominoplasty with limited undermining up to the umbilicus). (c) Thirty-two months postoperatively after first intervention (frontal/lateral) after the patient regained $12 \mathrm{~kg}$ in weight (note: scar positioning in submammary folds with excision of the bilateral subcostal scar) a
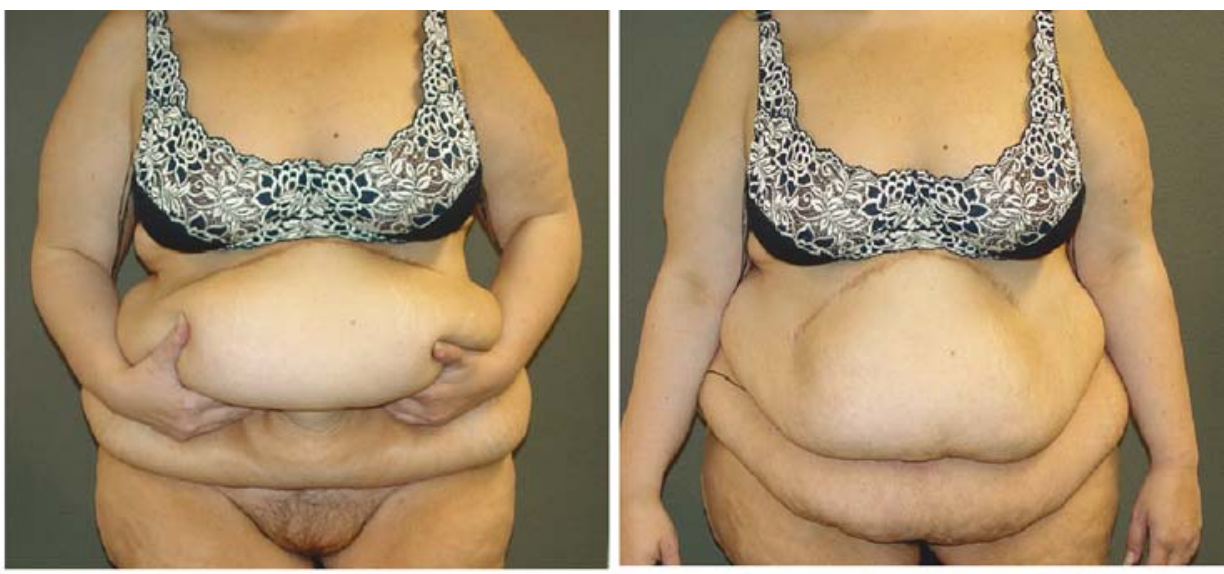

b
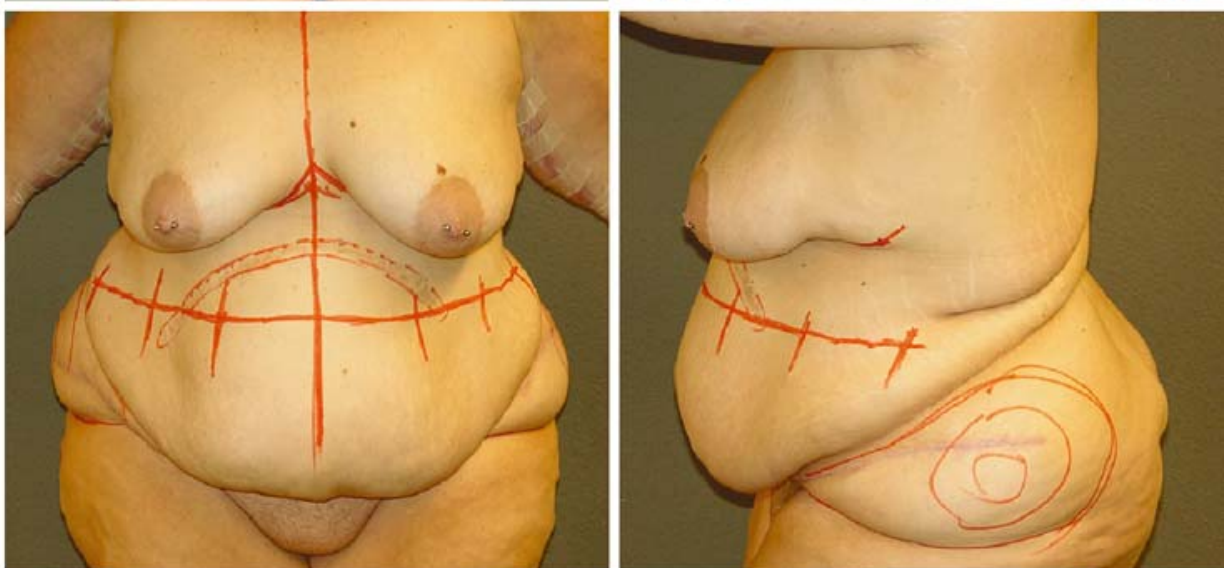

C
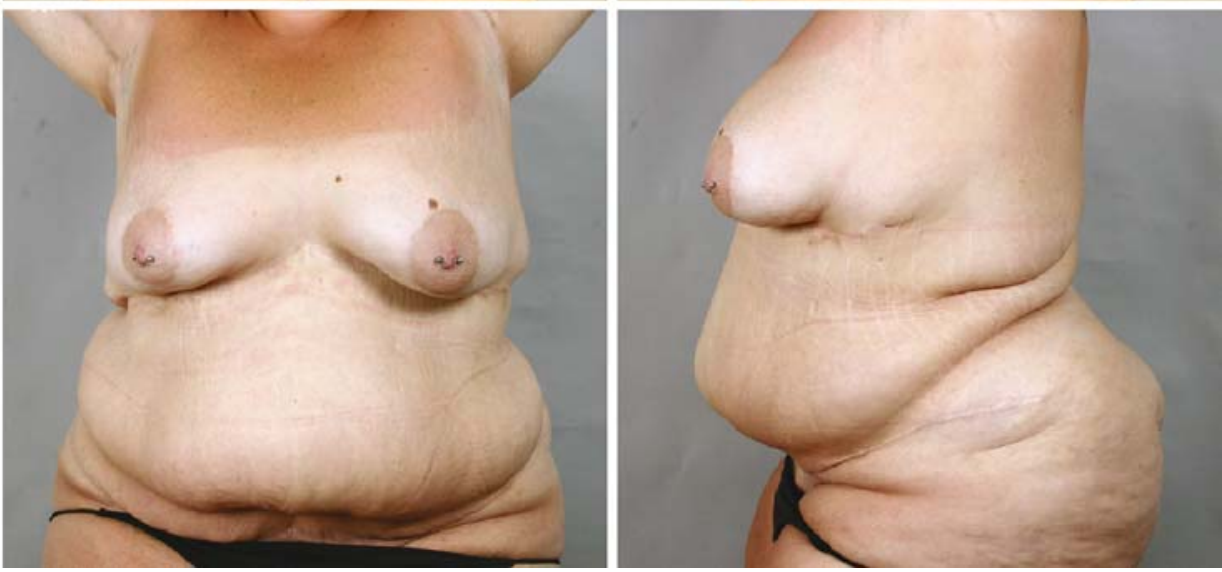
submammary folds and excision of the bilateral subcostal scars from the gastric bypass surgery are performed. Midline suture plication of the rectus fascia in case of diastasis can be performed in each of the steps if needed.

2. Abdominoplasty-cranial and caudal incision-onestaged procedure

Preoperatively, several paraumbilical perforators are identified by color duplex imaging. The paraumbilical area is circumcized, including the preoperatively marked perforators. Then an incision pursuant to a low transverse abdominoplasty is made low in the inguinal folds and suprapubic region. Through another incision placed along the submammary folds, an excision of the old transverse scar is performed. Excess skin resection follows from cranial and from caudal by preservation of a central island flap whose blood supply is ensured by the paraumbilical perforators. The options for suture placation of the rectus fascia are limited by the central skin island.

3. Perforator sparing abdominoplasty

The abdominoplasty procedure has been described in detail before [6]. Basically, the operative procedure was done according to Pitanguy. To prevent hypoperfusion of the flap, selective dissection of periumbilical abdominal wall perforator vessels is performed to secure flap blood supply. These perforators are visualized preoperatively by color duplex imaging. Flap undermining up to the xyphoid process is done around those perforator vessels. Through an extensive perforator preparation, sufficient flap mobility without perforator tension or traction is achieved. A full plication of the rectus fascia is possible if needed.

Duplex imaging is done as previously described $[7,8]$. The patient is examined supine.
4. Fleur-de-Lys abdominoplasty with horizontal to vertical scar transposition [9-11]

This technique is performed as described by Dellon et al. [9]. It combines vertical and horizontal resections to restore the abdominal contour to the upper and lower abdomen and the mons pubis. The procedure is especially suggested for patients with a huge panniculus and supraumbilical dermatochalasis. After resection of a cloverleaf-like panniculus, lateral tissue excess is mobilized and transposed medially, thus converting the transverse subcostal scar into a vertical scar. Blood supply of the flap is ensured by intercostal vessels. Full plication of the rectus fascia is possible if needed.

\section{Case Reports}

Case 1 (abdominoplasty, two-staged procedure): A 33year-old female diabetic patient underwent gastric banding and later gastric bypass surgery for morbid obesity (height $177 \mathrm{~cm}$, weight $185 \mathrm{~kg}$, body mass index [BMI] $59.1 \mathrm{~kg} / \mathrm{m}^{2}$ ). A bilateral subcostal incision was used for bypass surgery. Four years later, she presented for secondary body contouring surgery (lost $48 \mathrm{~kg}$, weight $137 \mathrm{~kg}$, BMI $43.7 \mathrm{~kg} / \mathrm{m}^{2}$ ) (Fig. 1).

In a first procedure, a limited low transverse abdominoplasty with undermining of the skin flap up to the umbilicus with sacrifice of periumbilical perforators (weight of resected tissue: $3.6 \mathrm{~kg}$ ) as well as resection of excess skin of the upper arms was performed. Postoperatively, we noticed a minor wound dehiscence in the suprapubic region, which healed by secondary intention. In a second procedure 6 months later, an inverted abdominoplasty with scar positioning in the submammary folds and excision of the bilateral subcostal scars from the gastric bypass surgery was performed (weight of resected tissue: $4.3 \mathrm{~kg}$ ). In the same operative sitting, suction-
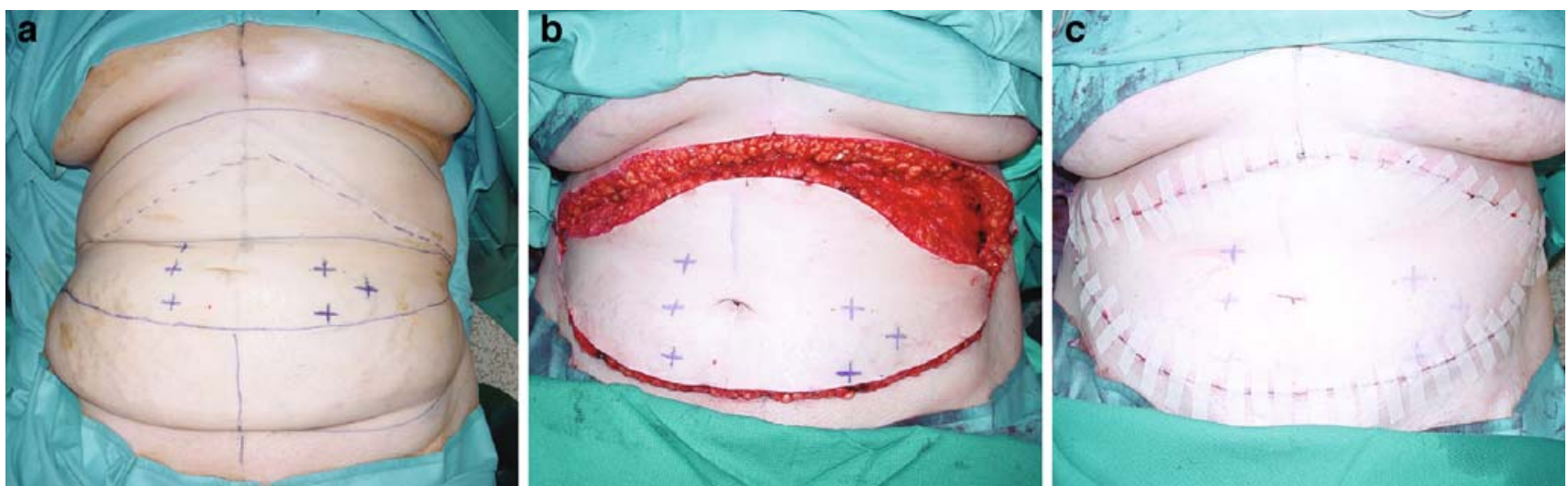

Fig. 2 (a) Preoperative planning with suprapubic and submammary incisions and six marked perforator vessels on periumbilical skin island (asterisks). (b) Intraoperative view after supra- and infraumbilical excess skin resection. (c) Result after layered wound closure 
lipectomy of both flanks was performed. Unfortunately, in the time period between the first procedure and the second, the patient gained $12 \mathrm{~kg}$, leading to a suboptimal tightening effect of the lower abdomen.

Case 2 (abdominoplasty, cranial and caudal incision, onestaged procedure): A 61-year-old female underwent gas- trointestinal bypass surgery for morbid obesity (height $166 \mathrm{~cm}$, weight $137 \mathrm{~kg}$, BMI $50 \mathrm{~kg} / \mathrm{m}^{2}$ ). A bilateral subcostal incision was used for this surgery. Seven years later, she presented for abdominoplasty and excess skin resection (weight loss $38 \mathrm{~kg}$, weight $99 \mathrm{~kg}$, BMI $35.9 \mathrm{~kg} / \mathrm{m}^{2}$ ). Abdominoplasty was performed as follows: Preoperatively, six paraumbilical perforators were visualized by color
Fig. 3 Perforator sparing abdominoplasty. (a) Tightening effect through resection of excess panniculus (note: the scar resulting from the open gastric bypass is pulled caudally to the central part of the abdominal wall). (b) Intraoperative view showing the umbilicus and two dissected peri-umbilical perforators. (c) Preoperative views (frontal, lateral). (d) Postoperative views 4 months postoperatively (frontal, lateral)
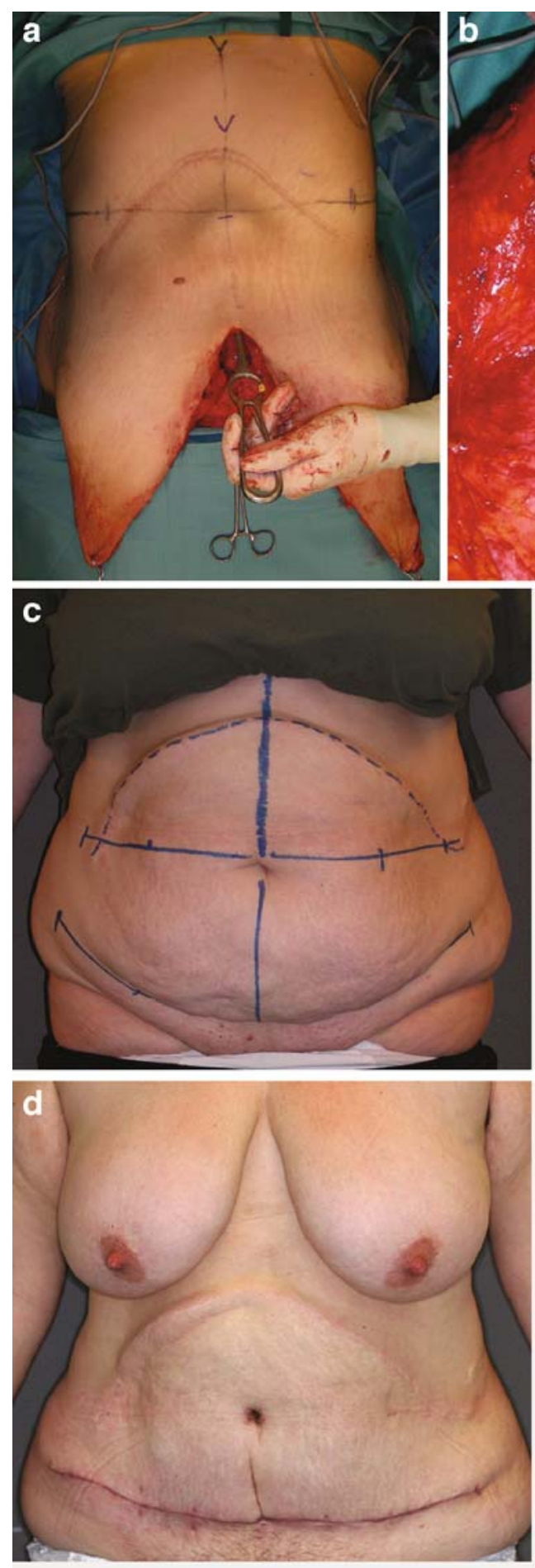
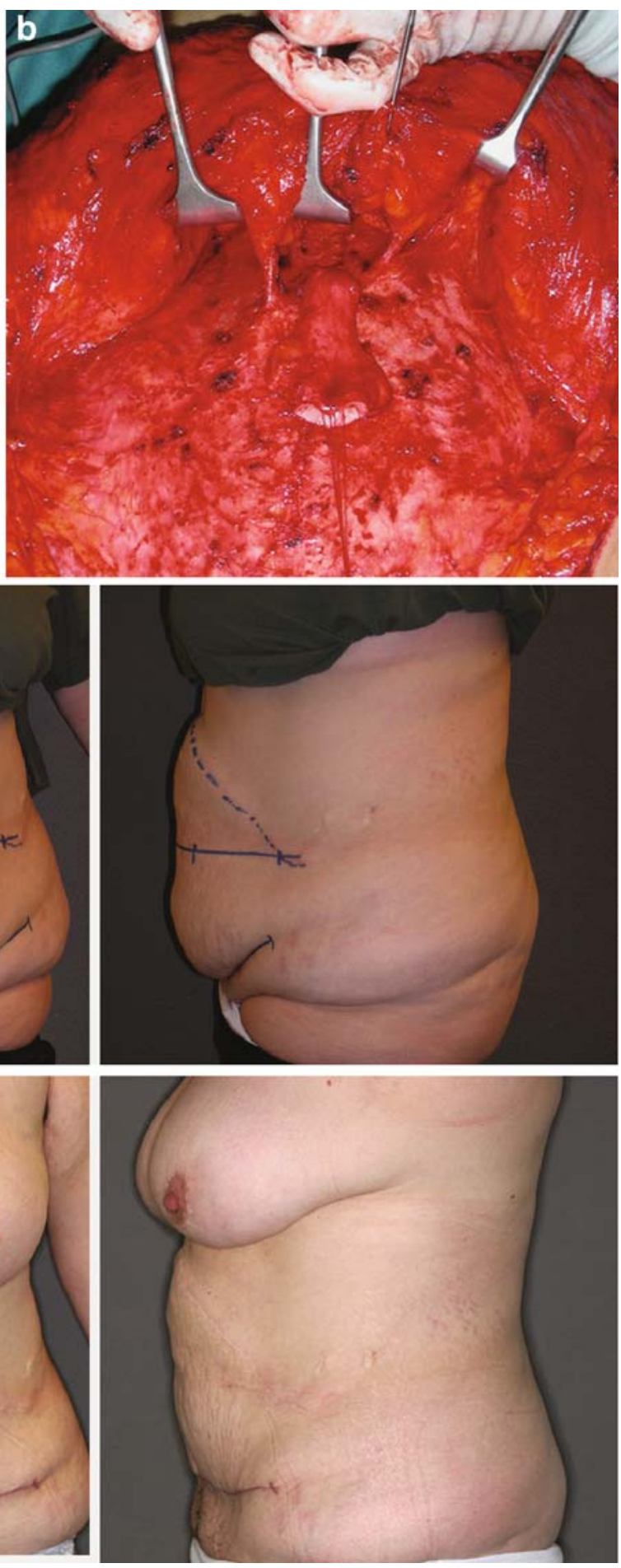

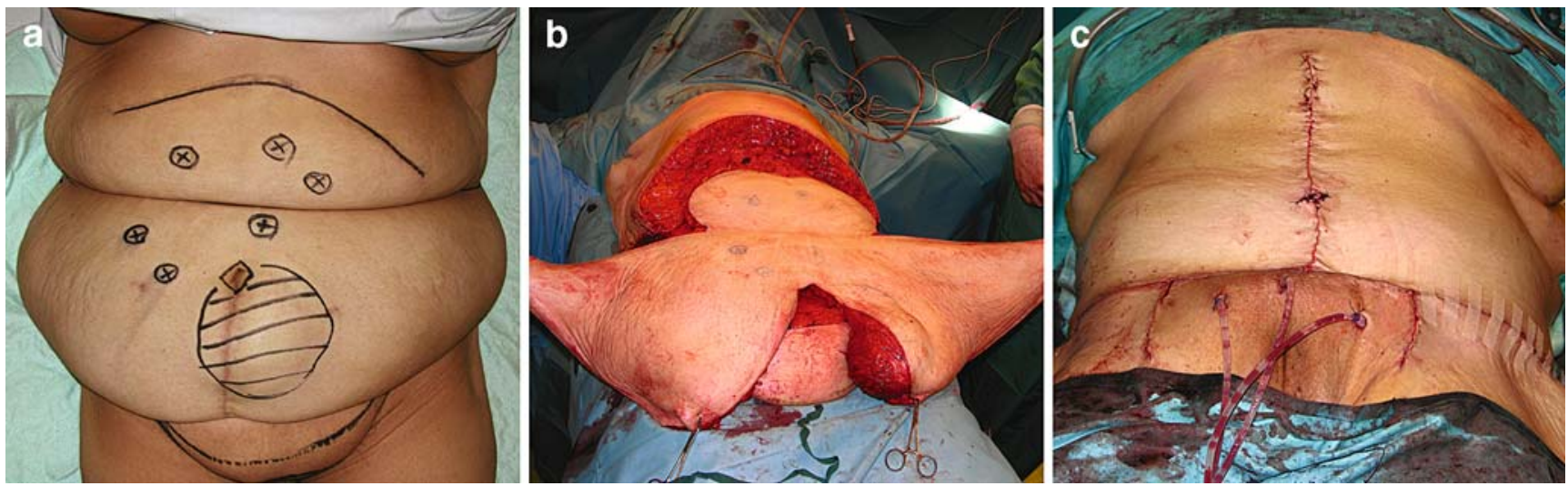

Fig. 4 Fleur-de-Lys abdominoplasty intraoperative views. (a) Preoperative view with abdominal perforators marked. (b) Resected excess cloverleaf like panniculus in situ. (c) View of the abdomen after layered wound closure (note excellent tightening effect)

duplex imaging. A Siemens Sonoline VERSA PRO device (Siemens, Munich, Germany) was used.

The paraumbilical area was circumcized including the marked perforators. Then an incision was made low in the inguinal folds and suprapubic region, and another incision was made along the submammary folds. Excess skin resection was performed from cranial and from caudal, and the skin island with six perforators was preserved (weight of resected tissue: $2.8 \mathrm{~kg}$ ) (Fig. 2). A doublelayered wound closure over suction drains was done.

Case 3 (perforator sparing abdominoplasty): A 32-yearold female underwent gastrointestinal bypass surgery for morbid obesity (height $160 \mathrm{~cm}$, weight $130 \mathrm{~kg}$, BMI $50.8 \mathrm{~kg} / \mathrm{m}^{2}$ ). A bilateral subcostal incision was used for this surgery. Two years later, she presented for abdominoplasty and excess skin resection (weight loss $58 \mathrm{~kg}$, weight $72 \mathrm{~kg}$, BMI $28.1 \mathrm{~kg} / \mathrm{m}^{2}$ ). A perforator-sparing abdominoplasty was performed as previously described [6]. This included dissection of three major periumbilical perforators (two lateral to the umbilicus, one cranio-lateral to the umbilicus) with tunneling through the rectus fascia and muscles and ligation of the cranial branch of each perforator (weight of resected tissue: $1.8 \mathrm{~kg}$ ) (Fig. 3).

Case 4 (modified Fleur-de-Lys abdominoplasty): A 45year-old female underwent gastrointestinal bypass surgery for morbid obesity (height $166 \mathrm{~cm}$, weight $181 \mathrm{~kg}$, BMI $65.3 \mathrm{~kg} / \mathrm{m}^{2}$ ). A bilateral subcostal incision was used for this surgery. Two years later, she presented for abdominoplasty and excess skin resection (weight loss $86 \mathrm{~kg}$, weight $95 \mathrm{~kg}$, BMI $34.5 \mathrm{~kg} / \mathrm{m}^{2}$ ).

Fleur-de-Lys abdominoplasty was performed as described above (weight of resected tissue $12.1 \mathrm{~kg}$ ). Suture plication of the rectus fascia was done, and layered wound closure over suction drains was performed (Fig. 4). Postoperatively, we noticed a minor wound dehiscence, which healed by secondary intention.

\section{Results}

All cases showed uneventful postoperative courses and were successful in terms of the esthetic and functional result. We observed minor wound dehiscences in patients number 1 and number 4 , which were managed conservatively. Neither partial nor full thickness flap necroses occurred.

\section{Discussion}

Abdominoplasty implies a significant impairment of the vascular supply of a considerable part of the abdominal flap [12]. In esthetic abdominoplasty, extended flap undermining up to the costal margin is the surgical standard [13]. This is not always applicable in patients being referred for abdominoplasty after open gastrointestinal bypass surgery because they occasionally present with a long transverse supraumbilical or subcostal scar that compromises blood supply from the superior epigastric arteries. For this reason and because of their comorbidities, these patients are especially demanding, and as reported by De Castro et al. they have an increased risk for partial flap necrosis when full abdominoplasty is performed [4].

Taylor et al. [14] have also reported that patients requiring surgical skin excision after massive weight loss for functional and/or esthetic reasons are challenging, and need an individualized approach. Different operative techniques have been proposed to preserve abdominal flap blood supply and reduce postoperative complications $[5,15,16]$. Among these, techniques preserving the periumbilical rectus abdominis perforator vessels proved to reduce postoperative wound complications [17] and are suitable also for patients after open gastrointestinal bypass surgery [6].

In the following, we weigh the advantages and drawbacks of each of the four described techniques. The characteristics of each technique are summarized in Table 1. 
Table 1 Overview of advantages and drawbacks of different abdominoplasty techniques after open gastric bypass with transverse subcostal incision

\begin{tabular}{|c|c|c|c|c|}
\hline & $\begin{array}{l}\text { Abdominoplasty, } \\
\text { two-staged procedure }\end{array}$ & $\begin{array}{l}\text { Abdominoplasty, cranial and caudal } \\
\text { incision, one-staged procedure }\end{array}$ & $\begin{array}{l}\text { Perforator sparing } \\
\text { abdominoplasty }\end{array}$ & $\begin{array}{l}\text { Modified Fleur-de-Lys } \\
\text { abdominoplasty }\end{array}$ \\
\hline Perforator sparing & - & + & + & - \\
\hline \multicolumn{5}{|l|}{ Need for } \\
\hline microsurgical skills & - & - & + & - \\
\hline \multicolumn{4}{|l|}{ Suture plication of } & + \\
\hline Tightening effect & ++ & + & ++ & +++ \\
\hline \multicolumn{5}{|l|}{ Resection of the } \\
\hline bypass scar & + & + & - & $(+)$ \\
\hline $\begin{array}{l}\text { Postoperative scar } \\
\text { positioning }\end{array}$ & $\begin{array}{l}\text { Submammary folds and } \\
\text { low inguinal folds }\end{array}$ & $\begin{array}{l}\text { Submammary folds and } \\
\text { low inguinal folds }\end{array}$ & Low inguinal folds & $\begin{array}{l}\text { Vertical midline and } \\
\text { low inguinal folds }\end{array}$ \\
\hline \multicolumn{5}{|l|}{ Amount of excess } \\
\hline tissue resectable & ++ & + & + & +++ \\
\hline Abdominal skin sensibility & - & - & ++ & + \\
\hline
\end{tabular}

1. Abdominoplasty, two-staged procedure

Abdominal body contouring surgery with a two-staged procedure as described consists of two relatively easy procedures with no microsurgical skills required. To yield a good tightening effect, a disruption of most of the abdominal wall perforators has to be performed. Suture plication of the rectus muscles is possible in two separate steps: first, in the lower abdomen, then later in the upper part. The scars can be positioned discretely in the submammary folds and low in the inguinal folds. Naturally, hiding of the submammary scar is only possible in females. The surgeon should make sure that excess skin resection can be performed in such a way that the original subcostal scar is included in the resected excess skin. Beside the two-staged procedure itself, the main disadvantage is a severely compromised sensitivity of the abdominal skin between the two transverse scars. However, a very good tightening effect can be achieved by this technique. A limiting factor of this technique is the possibility of regaining weight in the time between the first and the second procedure. In this case, an optimal tightening effect of the lower abdomen is difficult to achieve through the submammary incision.

2. Abdominoplasty, cranial and caudal incision, onestaged procedure

This single-stage technique is very safe and quick to perform. To be sure to include at least one perforator in proximity to the umbilicus, preoperative marking by color duplex imaging can be performed. This way a well-perfused skin island around the umbilicus is left without having to dissect perforators microsurgically. However, the tightening effect of the abdominal wall is limited and plication of rectus fascia cannot be performed to a full extent because of the overlying skin island in the central part of the abdomen. In most cases, the old bypass scar can be included in the cranial excess tissue resection. Positioning of the new scars is performed in a similar way as in the two-staged procedure. The sensibility of the skin island is severely compromised.

3. Perforator sparing abdominoplasty

From our experience, actual perforator dissection through the fascia combined with muscle tunneling and ligation of the ascending branch of the perforator as done in perforator sparing abdominoplasty [6] may yield favorable esthetic results, but requires basic microsurgery skills. In cases with extensive supraumbilical excess panniculus, only insufficient flap mobility may be achieved despite extensive perforator dissection. The limiting factor hereby is represented by the actual lengths of the dissected perforators because they may be disrupted by too much traction when pulling the abdominal flap caudally for good tightening. Suture placation of the rectus muscles can be performed easily. The resulting new scar is positioned low in the inguinal folds; however, the old scar from the gastric bypass moves caudally and often to the central part of the abdomen. The tightening effect of this method is excellent; however, the bypass scar can become even more accentuated. The method yields excellent results in terms of abdominal skin sensibility.

4. Modified Fleur-de-Lys abdominoplasty

Modified Fleur-de-Lys abdominoplasty is very suitable to resect huge excess panniculus tissue in a single-stage 
procedure. A skilled surgeon can transform the old transverse subcostal scar resulting from the open gastric bypass into a vertical scar, which would have resulted anyway because of the nature of the technique. To the authors, the vertical scar seems less conspicuous than the transverse scar across the abdominal wall. The tightening effect is excellent and plication of the rectus fascia is easy to perform in case of true diastasis of the rectus muscles. In addition, excess tissue of the flanks can be removed as well. The sensibility of the abdominal skin is impaired, but still better than after techniques with cranial and caudal incisions.

All techniques in an individualized operative abdominal wall-contouring concept after open gastric bypass through a transverse incision in the upper abdomen can yield good esthetic and functional results. The surgeon always has to keep in mind the vascular anatomy of the abdominal wall and try to preserve the remaining abdominal wall perfusion. The pros and cons of each technique described have to be weighed up carefully to choose the optimal operative option. Despite massive weight loss, patients often still carry comorbidities like hypertension or diabetes. However, in none of our cases major complications occurred, but we noticed that in the two cases that disrupt abdominal wall perfusion (Fleur-de-Lys abdominoplasty; abdominoplasty, twostaged procedure), two minor wound dehiscences occurred. We conclude that through a careful selection of different surgical techniques, good functional and esthetic results can be achieved with no apparent additional risk of complications.

\section{References}

1. Alvarez-Cordero R, Aragon-Viruette E. Incisions for obesity surgery: a brief report. Obes Surg. 1991;1:409-11.
2. Jones KBJ. The superiority of the left subcostal incision compared to mid-line incisions in surgery for morbid obesity. Obes Surg. 1993;3:201-5.

3. Jones KBJ. The left subcostal incision revisited. Obes Surg. 1998;8:225-8.

4. de Castro CC, Aboudib JJ, Salema R, Gradel J, Braga L. How to deal with abdominoplasty in an abdomen with a scar. Aesthet Plast Surg. 1993;17:67-71.

5. Huger WEJ. The anatomic rationale for abdominal lipectomy. Am Surg. 1979;45:612-7.

6. Rieger UM, Aschwanden M, Schmid D, Kalbermatten DF, Pierer G, Haug M. Perforator-sparing abdominoplasty technique in the presence of bilateral subcostal scars after gastric bypass. Obes Surg. 2007;17:63-7.

7. Chang BW, Luethke R, Berg WA, Hamper UM, Manson PN. Two-dimensional color doppler imaging for precision preoperative mapping and size determination of TRAM flap perforators. Plast Reconstr Surg. 1994;93:197-200.

8. Rand RP, Cramer MM, Strandness DEJ. Color-flow duplex scanning in the preoperative assessment of TRAM flap perforators: a report of 32 consecutive patients. Plast Reconstr Surg. 1994;93:453-9.

9. Dellon AL. Fleur-de-Lis abdominoplasty. Aesthet Plast Surg. 1985;9:27-32.

10. Ramsey-Stewart G. Radical "Fleur-de-Lis" abdominal after bariatric surgery. Obes Surg. 1993;3:410-4.

11. Duff CG, Aslam S, Griffiths RW. Fleur-de-Lys abdominoplastya consecutive case series. Br J Plast Surg. 2003;56:557-66.

12. Mayr M, Holm C, Hofter E, Becker A, Pfeiffer U, Muhlbauer W. Effects of aesthetic abdominoplasty on abdominal wall perfusion: a quantitative evaluation. Plast Reconstr Surg. 2004;114(6): 1586-94.

13. Grazer FM, Goldwyn RM. Abdominoplasty assessed by survey, with emphasis on complications. Plast Reconstr Surg. 1977; 59:513-7.

14. Taylor J, Shermak M. Body contouring following massive weight loss. Obes Surg. 2004;14(8):1080-5.

15. Matarasso A. Liposuction as an adjunct to a full abdominoplasty revisited. Plast Reconstr Surg. 2000;106:1197-202.

16. Saldanha OR, Souza Pinto EB, Mattos WN Jr, Pazetti CE, Lopes Bello EM, Rojas Y, et al. Lipoabdominoplasty with selective and safe undermining. Aesthet Plast Surg. 2003;27:322-7.

17. Graf R, de Araujo LR, Rippel R, Neto LG, Pace DT, Cruz GA. Lipoabdominoplasty: liposuction with reduced undermining and traditional abdominal skin flap resection. Aesthet Plast Surg. 2006;30:1-8. 